\title{
Hydrometeorological threshold conditions for debris flow initiation in Norway
}

\author{
N. K. Meyer ${ }^{1,2}$, A. V. Dyrrdal ${ }^{3}$, R. Frauenfelder ${ }^{4}$, B. Etzelmüller ${ }^{2}$, and F. Nadim ${ }^{1,4}$ \\ ${ }^{1}$ International Centre for Geohazards (ICG), c/o NGI, P.O. Box 3930 Ullevål Stadion, 0806 Oslo, Norway \\ ${ }^{2}$ University of Oslo (UiO), Department of Geoscience, P.O. Box 1047 Blindern, 0316 Oslo, Norway \\ ${ }^{3}$ Norwegian Meteorological Institute (met.no), P.O. Box 43 Blindern, 0313 Oslo, Norway \\ ${ }^{4}$ Norwegian Geotechnical Institute (NGI), P.O. Box 3930 Ullevål Stadion, 0806 Oslo, Norway \\ Correspondence to: N. K. Meyer (nkm@ngi.no)
}

Received: 19 January 2012 - Revised: 13 August 2012 - Accepted: 28 August 2012 - Published: 11 October 2012

\begin{abstract}
Debris flows, triggered by extreme precipitation events and rapid snow melt, cause considerable damage to the Norwegian infrastructure every year. To define intensity-duration (ID) thresholds for debris flow initiation critical water supply conditions arising from intensive rainfall or snow melt were assessed on the basis of daily hydrometeorological information for 502 documented debris flow events. Two threshold types were computed: one based on absolute ID relationships and one using ID relationships normalized by the local precipitation day normal (PDN). For each threshold type, minimum, medium and maximum threshold values were defined by fitting power law curves along the 10th, 50th and 90th percentiles of the data population. Depending on the duration of the event, the absolute threshold intensities needed for debris flow initiation vary between 15 and $107 \mathrm{~mm}$ day $^{-1}$. Since the PDN changes locally, the normalized thresholds show spatial variations. Depending on location, duration and threshold level, the normalized threshold intensities vary between 6 and $250 \mathrm{~mm} \mathrm{day}^{-1}$. The thresholds obtained were used for a frequency analysis of over-threshold events giving an estimation of the exceedance probability and thus potential for debris flow events in different parts of Norway. The absolute thresholds are most often exceeded along the west coast, while the normalized thresholds are most frequently exceeded on the west-facing slopes of the Norwegian mountain ranges. The minimum thresholds derived in this study are in the range of other thresholds obtained for regions with a climate comparable to Norway. Statistics reveal that the normalized threshold is more reliable than the absolute threshold as the former shows no spatial clustering of debris flows related to water supply events captured by the threshold.
\end{abstract}

\section{Introduction}

A debris flow is a form of rapid mass movement in which a combination of loose soil, rock, organic matter and water mobilize as a slurry that flows downslope (Innes, 1983; Rickenmann and Zimmermann, 1993; Hungr et al., 2008). Debris flows are commonly triggered by intense surface-water flow caused by heavy precipitation or rapid snow melt, leading to the erosion and mobilization of loose soil or rock on steep slopes. This means that three basic requirements have to be fulfilled simultaneously for them to occur: presence of steep slopes, availability of unconsolidated sediments and loose material, and unusually high supply of water (Innes, 1983; Iverson, 1997; Frattini et al., 2009). Debris flows start frequently as shallow slides in nearly-saturated soil that turn into flows. The high water supply causes saturation and loss of suction in unsaturated soils as well as a rapid increase in pore pressure in saturated soils, leading to a decrease in the shear strength of the sediments and triggering of the initial slide. It also plays a key role in the transition of the slide to flow.

Nearly all debris flows are triggered by hydrometeorological events, such as intense storms, prolonged rainfall and snow and glacier melt. However, on rare occasions, geological events such as earthquakes or volcanic disruptions also trigger debris flows (Innes, 1983; Keefer, 1984; Wieczorek, 1996; Rebetez et al., 1997; Crosta, 1998; Wieczorek and Glade, 2005). The most common triggers for debris flows in Norway are intense rainfall and rapid snow melt leading to high soil saturation and severe surface and subsurface runoff (Sandersen et al., 1996; Nadim et al., 2009). 
On a regional scale, it is common to estimate the local debris flow potential from statistical analysis of past triggering rainfall/snow melt events (Caine, 1980; Wieczorek and Glade, 2005; Guzzetti et al., 2007, 2008). Intensityduration (ID) thresholds are based on the assumption that, for a given duration, there exists a specific minimum rainfall intensity above which debris flows are likely to be triggered (Wieczorek and Glade, 2005). The so-called minimum threshold, sometimes referred to as the "safety threshold", is the lowest level below which a process is very unlikely to occur (Guzzetti et al., 2007; Baum and Godt, 2010). In most cases the intensity needed to trigger a debris flow, however, substantially exceeds the minimum threshold (Innes, 1983). This is why the maximum ID threshold is also of interest. The maximum threshold defines the level above which a process almost always occurs (Guzzetti et al., 2007; Dahal and Hasegawa, 2008).

Generally it can be observed that the wetter the region, the higher is the threshold for the intensity that is likely to trigger debris flows (Innes, 1983; Guzzetti et al., 2007; Nadim et al., 2009). This relationship reflects the adjustment of the slopes to the long-term precipitation regime (Wilson and Jayko, 1997; Nadim et al., 2009). To account for this spatial variability Cannon and Ellen (1985) introduced mean annual precipitation (MAP) to normalize the critical ID relationship. However, in recent years several studies showed that the normalization with respect to MAP might be inadequate. Even if the total amount of precipitation is higher in one region than in another, the average daily rainfall on a rainy day might be less (Wieczorek and Glade, 2005). Wilson and Jayko (1997) suggest, therefore, using the rainy day normal (RDN), i.e., the amount of precipitation typically falling on a day with precipitation. They show that the RDN is a better normalization parameter since it reflects the common intensities in a climatic region and correlates with moderate storms that might trigger debris flows.

In many parts of Norway, debris flows pose a serious threat to buildings and transport infrastructure. The Norwegian Public Road Administration (NPRA) reports that one third of all registered mass movements (including snow avalanches) resulted in total or partial road closures. Among the different mass movement types, debris flows had the largest consequences for road infrastructure (e.g., $25 \%$ of all pavement damages connected to mass movements were caused by debris flows). Debris flows are often related to extreme precipitation and flood events. In autumn 2005, the two extreme precipitation events "Kristin" and "Loke" triggered together, for example, almost 100 debris flows in Norway (Bjordal and Helle, 2011).

Using a small sample of 30 debris flow events, Sandersen et al. (1996) derived an intensity-duration threshold for debris flow initiation in Norway based on average intensities calculated from the total amount of precipitation over subjectively chosen critical durations. Their threshold indicates that debris flows initiate as soon as the precipitation sum equals
$8 \%$ of the mean annual precipitation (MAP) during 1 day. In practice, the threshold suggested by Sandersen et al. (1996) turns out to be too high for issuing warnings (T. Humstad, personal communication, 2011). Cepeda et al. (2010) derived a threshold for debris flows in the small Norangselva catchment located at the northwestern coast of Norway. He found that rainfall intensities exceeding $17 \mathrm{~mm}$ in 1 day might trigger debris flows. However, this threshold is very local and cannot be extrapolated to the entire country.

The aim of this study was, therefore, to derive intensityduration (ID) thresholds for debris flow initiation in Norway based on a large statistical data population. A comprehensive database with over 600 debris flow events recently became available as well as gridded data providing spatially continuous information on water supply for the entire country. Both data sets in combination provide the unique opportunity to estimate critical initiation conditions. We assume that the integration of the factor snow for the definition of critical water supply ID relationships will enhance the temporal accuracy of the hydro-meteorological information.

\section{Data basis and method development}

\subsection{Digital elevation model (DEM)}

The digital elevation model (DEM) used in this study is provided by the Norwegian Mapping Authority (Statens Kartverk, 2011) and has a resolution of $10 \mathrm{~m} \times 10 \mathrm{~m}$. The elevation information is based on contour lines, elevation points, coast lines, river lines and water surface polygons. In populated areas the underlying contour lines have a spacing of $5 \mathrm{~m}$ (corresponds to FKB-H5 map) while unsettled areas are covered by contour lines with a spacing of $20 \mathrm{~m}$ (corresponds to N50 map). The uncertainty in elevation information ranges between $2 \mathrm{~m}$ and $6 \mathrm{~m}$ depending on the location and quality of the underlying data in settled and unsettled areas, respectively. The DEM covers all of mainland Norway including the coastal islands (Statens Kartverk, 2011).

\subsection{Gridded hydro-meteorological data}

All climate data used for this study are provided by the Norwegian Meteorological Institute (met.no) and the Norwegian Water and Energy Directorate (NVE) (Engeset et al., 2004; Tveito et al., 2005; available via www.seNorge.no). The climate grids extend in time back to 1957 and are updated on a daily basis. The maps are created from daily observations of temperature and precipitation interpolated to a $1 \mathrm{~km} \times 1 \mathrm{~km}$ grid (hereafter referred to as climate grids).

The temperature grid is interpolated from daily temperature measurements reported by 235 meteorological stations using residual kriging. Since meteorological stations are underrepresented at higher elevations the interpolation method incorporates assumptions about the temperature lapse rate. Residual kriging was found to be a good method to account 
for the lack of information at higher elevations, except during inversions in winter (Tveito et al., 2005).

The precipitation grid is interpolated from daily precipitation measurements reported by approximately 400 meteorological stations and corrected for the windrelated gauge undercatch of snow (Tveito et al., 2005). The spatial interpolation of precipitation was conducted by applying irregular triangular networks (TINs) for the parameters precipitation and elevation. Both TINs were combined and transformed into $1 \mathrm{~km} \times 1 \mathrm{~km}$ grids by adding a vertical precipitation gradient of $10 \%$ for every $100 \mathrm{~m}$ altitude up to $1000 \mathrm{~m}$ a.s.l. At elevations higher than $1000 \mathrm{~m}$ a.s.l., the vertical precipitation gradient is estimated to be $5 \%$ for every $100 \mathrm{~m}$ altitude (Tveito et al., 2005). There are few meteorological stations at higher elevations and the precipitation would be underestimated without accounting for this altitude correction (Førland, 1979). The temperature and the precipitation grids serve as input to a snow model that calculates the changes in the snow conditions due to temperature and precipitation (Engeset et al., 2004). The snow model uses a relatively simple process-based method to calculate the snow water equivalent, snow depth, snow bulk density and liquid water in snowpack. Evaluation showed overestimation of the snow water equivalent and snow bulk density. These systematic biases can be reduced by using relative units instead of absolute values. Generally, the snow model was found to be a good way to produce national snow maps of high spatio-temporal resolution (Saloranta, 2012).

\subsection{Derivation of water supply (WS) data}

The hydro-meteorological conditions in advance of each debris flow are extracted from national grids showing information on "rain and snow melt". This data will be referred to as water supply (WS) throughout this paper. This water supply represents the amount of available water on one day in millimeters $[\mathrm{mm}]$ derived from rainfall and snow melt "on-site" at a specific location (as compared to the flow accumulation which also considers run-off related supply from upstream areas). Information on water supply is available on a daily basis and sums up the actual amount of rainfall on that specific day plus the amount of released snow melt water on days with temperatures above $0{ }^{\circ} \mathrm{C}$. However, on days with temperatures below $0^{\circ} \mathrm{C}$, the amount of water provided by precipitation is temporarily stored. This stored water is first released to the cell when the temperature rises above $0{ }^{\circ} \mathrm{C}$. Over an entire hydrological year, the sum of precipitation and the sum of water supply should be equal since all water stored in the form of snow is going to be released during spring and summer. During the winter season, however, water provided by snow can be released with a significant time delay (Wieczorek, 1996; Wieczorek and Glade, 2005; Jakob and Weatherly, 2003).
Raster information regarding the precipitation day normal (PDN) is used for normalization:

$\mathrm{PDN}=\mathrm{MAP} / \mathrm{APD}$

where MAP is the mean annual precipitation and APD the average number of precipitation days per year (Fig. 1).

The precipitation day normal is an indicator for the intensity with which water is supplied over a year and represents the hydrological conditions the landscape of a region is adapted to. The main difference from the rainy day normal (RDN) is that, besides rainfall, also water supplied by snow melt is considered. The PDN was calculated for the normal period 1961-1990 and extracted for all debris flow locations.

\subsection{Slide database}

The Norwegian slide database, which records instances of all types of landslides as well as snow avalanches, consists of almost 33000 entries (Jaedicke et al., 2009, available via www.skrednett.no). Information on the recorded slides was gathered primarily from the national road and railway authorities, but also from governmental organizations and consulting firms who are in charge of post-slide investigations. All data are stored within a GIS point layer providing information on time of occurrence, location and type of movement. For some of the slides more detailed information such as the run-out distance or the slide volume is also given. Within the slide database, 710 events are recorded as single debris flow events at their point of deposition. The dates of the documented events range from 1900 to 2008 with a clear peak of recorded events between 1979 and 2007. The accuracy of the reported event times is given as additional information and differs widely from event to event. In total, 648 events documented between 1976 and 2008 were used for this study all of which had an event time accuracy of 30 minutes or less. Figure 2 shows the spatial distribution of these 648 debris flows. A cluster of documented debris flows is clearly observable on the west coast of the country where the mean annual precipitation is high and deeply incised fjords are prominent.

To extract the relevant information for the triggering conditions of a specific debris flow, the hydro-meteorological conditions at the initiation area in advance of the debris flow event have to be known. Since the debris flow locations were usually recorded at the area of deposition, it was necessary to relocate these debris flow points to their potential initiation areas (Fig. 3). To identify the most likely initiation areas, the watershed for each documented debris flow point (with a buffer of $100 \mathrm{~m}$ radius) was calculated. The criteria for finding the likely initiation points within this watershed were based on slope, elevation and flow length with respect to the documented deposition point. Cells with slope of more than $25^{\circ}$ were extracted from the watershed; $25^{\circ}$ is known as a likely minimum slope inclination for debris flow initiation (e.g., Rapp and Nyberg, 1981; Innes, 1983; Zimmermann, 1990; Rieckenmann and Zimmermann, 1993; Hungr 


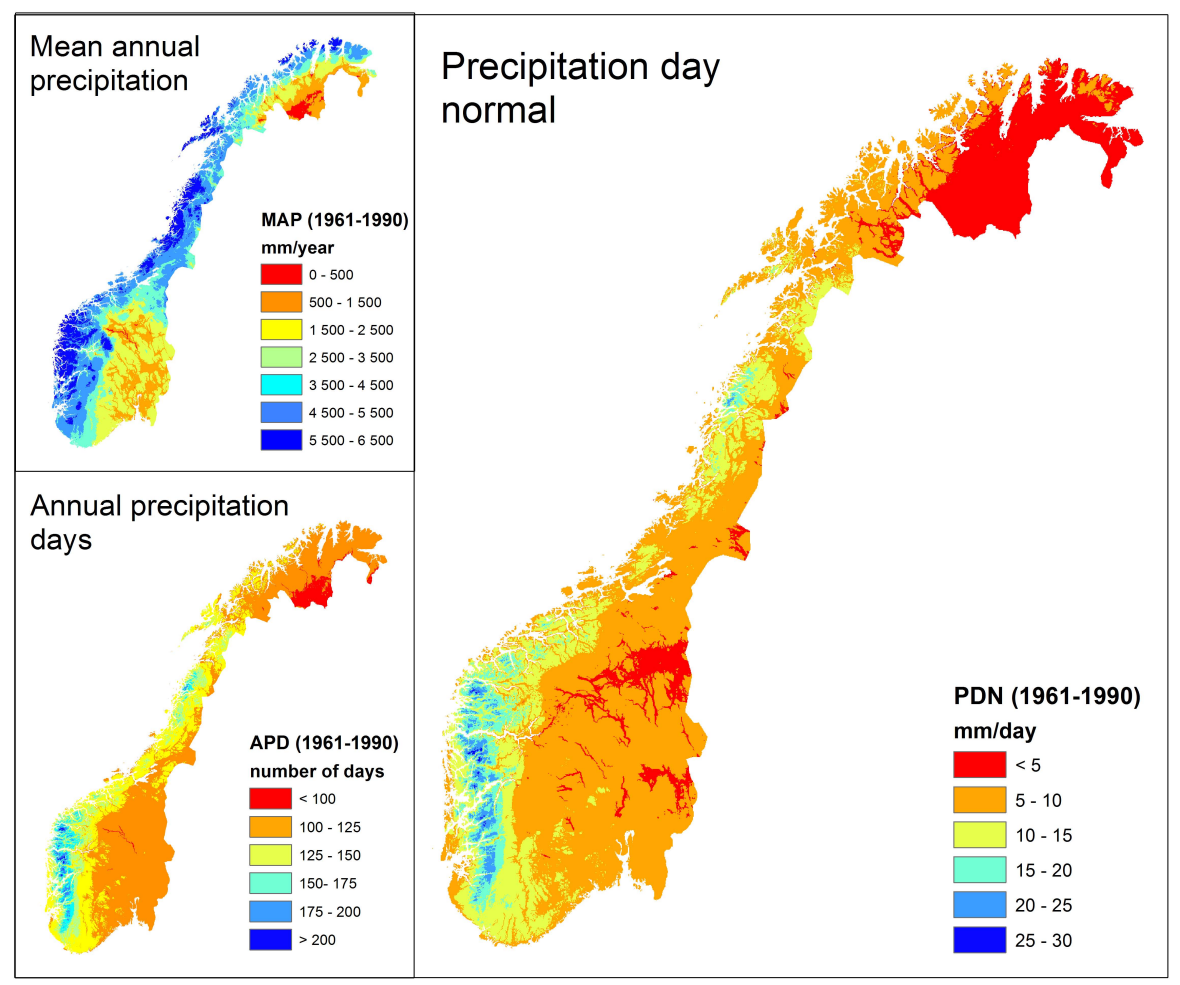

Fig. 1. Grids used for normalization of water supply data at debris flow locations: the precipitation day normal (PDN) is calculated by dividing the mean annual precipitation (MAP) by the average number of precipitation days per year (APD) and represents the typical amount of precipitation on a precipitation day.

et al., 2008). For the remaining potential initiation cells, the flow length to the reported deposition point was calculated. From the database, a travel distance of $2500 \mathrm{~m}$ was identified as the longest documented travel distance for a debris flow in Norway. However, only 6 of the 648 entries contained information on travel distance. A literature review showed that travel distances of debris flows exceeding $3000 \mathrm{~m}$ are rather unlikely (Hungr et al., 2008). Cells with flow lengths of more than $3000 \mathrm{~m}$ were, therefore, excluded. The highest point in the extracted initiation area was then selected as the initiation point of the corresponding debris flow in this study.

From the 648 debris flow initiation points a number of 502 could be used to extract water supply information for the event day 4 weeks ( 28 days) before each debris flow event. 146 records had to be discarded due to missing water supply information or low data quality (see Sect. 5.1).

\subsection{Definition of intensity-duration (ID) relationships}

To define a valid intensity-duration (ID) threshold, it is necessary to determine the critical intensities related to durations of the rainfall and/or snow melt events which triggered debris flows. The choice of the duration is often done by a subjective definition of the triggering events, e.g., from the approximate point in time where heavy rainfall started (Guzzetti et al., 2007). In order to define event durations more objectively, we extracted the relevant time-dependent data directly from the gridded precipitation data (see Sect. 3.2). Thereby we obtained the critical water supply duration by using the maximum average intensity $\left[\mathrm{mm} \mathrm{day}^{-1}\right.$ ] prior to each debris flow event, also known as the maximum antecedent water supply (Table 1).

$\mathrm{ID}=\max \left(\mathrm{WS}_{\mathrm{C}} / \mathrm{D}\right) \sim \mathrm{D}$

where ID is the intensity-duration relationship used for threshold definition, $\mathrm{WS}_{\mathrm{C}}$ is the cumulative water supply in the time period prior to the debris flow and D is the corresponding duration in days. Intensity-duration relationships were calculated for each day in four weeks (28 days) in advance of each debris flow event and the maximum value was chosen for threshold definition.

\subsection{Threshold definition}

The intensity-duration (ID) relationships for the 502 debris flow events served as input for the definition of minimum, medium and maximum thresholds. All three threshold levels are calculated for the absolute and normalized intensities over a range of 1 to 7 days and can only be applied over this period of time. For longer durations the amount of 


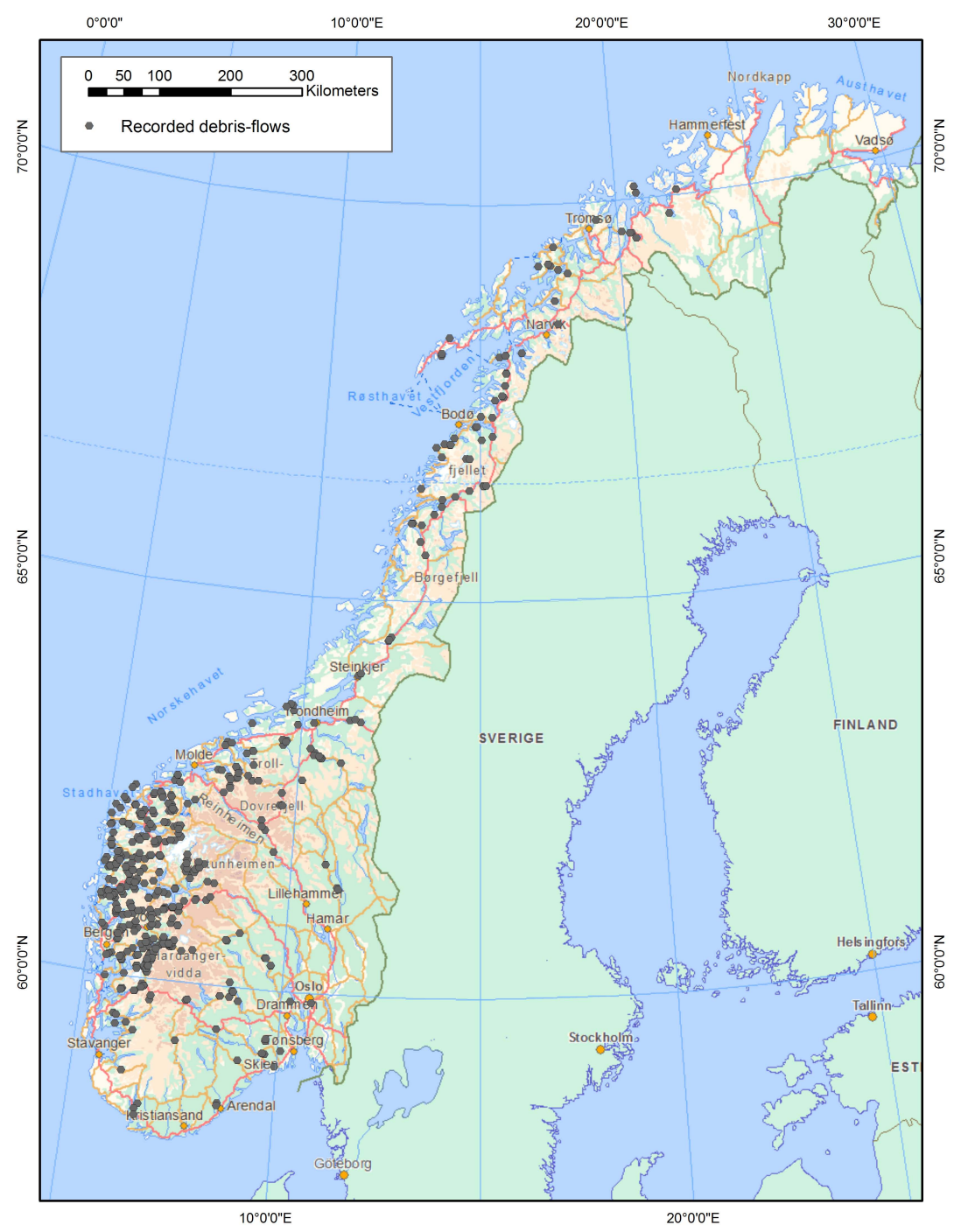

Fig. 2. Spatial distribution of the 648 debris flows analyzed in this study; temporal coverage of analyzed events $=1976-2008$.

data is too low to achieve a reliable threshold curve. Power laws of the form $\mathrm{I}=a * D^{b}$ are the most common forms for ID threshold curves described in the literature (Guzzetti et al., 2007; Brunetti et al., 2010). The ID relationships defined by this function are linear in a log-log plot. The absolute threshold plot shows the absolute water supply intensity $\left[\mathrm{mm} \mathrm{day}^{-1}\right]$ over the corresponding duration (Fig. 4), while the normalized plot shows the absolute water supply intensity $\left[\mathrm{mm} \mathrm{day}^{-1}\right]$ divided by the local precipitation day normal (PDN) and plotted against the duration (Fig. 5). As noted before, normalization was carried out to account for differences in local climate.

Data on non-events would have been of help to handle uncertainties related to the event database (see Sect. 5.1). Unfortunately such data were not available and we decided to aim for a minimum threshold that captures approximately $90 \%$ of the 502 obtained ID relationships (allowing obtained water supply intensities in the very low range to be potentially wrong for one or the other reason). The minimum threshold was obtained by calculating the 5 th and the 15 th intensity percentiles for 1 to 7 days duration applying a 3-day moving average filter to the intensity-duration relationships. The method used for the definition of the medium and maximum thresholds was similar. The medium threshold aims to capture $50 \%$ of the obtained ID relationships. Accordingly, the threshold curve was fitted through the 3-day moving average of the 45th and the 55th percentiles over 7 days of duration. The maximum threshold aims to capture $10 \%$ of the ID relationships and accordingly the 3-day moving average of the 85th and the 95th percentiles are used. Comparable approaches that use percentile regressions for threshold definition are performed by, e.g., Guzzetti et al. (2007) and Saito et al. (2010). 
Table 1. Individual series of antecedent water supply data for a debris flow event that occurred near Vang (central Norway) on 04.05.2008: The cumulative water supply [mm] and the corresponding average intensities [mm day ${ }^{-1}$ ] are calculated for the 28 days in advance of an event. The found maximal cumulative average intensity $\left(\mathrm{WS}_{\mathrm{C}} / \mathrm{D}\right)$ and the corresponding duration (D) (printed bold) are used as input for the threshold definition.

\begin{tabular}{llll}
\hline $\begin{array}{l}\text { Duration [day] } \\
(\mathrm{D})\end{array}$ & $\begin{array}{l}\text { Water supply } \\
{[\mathrm{mm}]}\end{array}$ & $\begin{array}{l}\text { Cumulative water supply } \\
{[\mathrm{mm}]\left(\mathrm{WS}_{\mathrm{C}}\right)}\end{array}$ & $\begin{array}{l}\begin{array}{l}\text { Cumulative average intensity } \\
{\left[\mathrm{mm} \mathrm{day}^{-1}\right]}\end{array} \\
\left(\mathrm{WS}_{\mathrm{C}} / \mathrm{D}\right)\end{array}$ \\
\hline $1_{\text {Event }}$ & 13 & 13 & 13 \\
2 & 23 & 36 & 18 \\
3 & 33 & 69 & 23 \\
$\mathbf{4}$ & 38 & 107 & $\mathbf{2 7}$ \\
5 & 21 & 128 & 26 \\
6 & 23 & 151 & 25 \\
7 & 20 & 171 & 24 \\
8 & 8 & 179 & 22 \\
9 & 0 & 179 & 20 \\
10 & 0 & 179 & 18 \\
{$[\ldots]$} & {$[\ldots]$} & {$[\ldots]$} & {$[\ldots]$} \\
28 & 38 & 207 & 27 \\
\hline
\end{tabular}

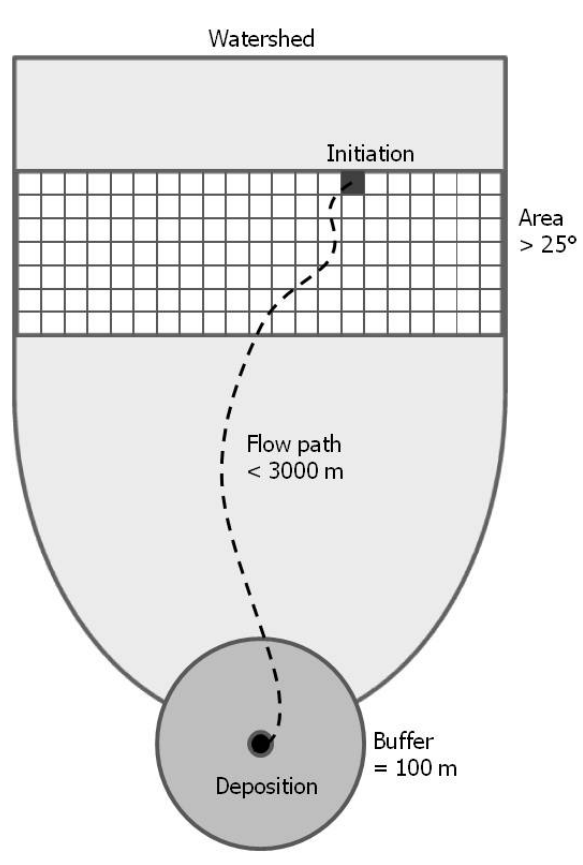

Fig. 3. Schematic illustration of the parameters used for the relocation of recorded debris flows from the deposition to a likely initiation area.

In our study the minimum threshold is interpreted as the lowest intensity-duration relation that is able to trigger debris flows. However, occurrences below this threshold are possible as the lowest intensity values were left out due to uncertainties related to the data quality. The medium threshold is interpreted as the intensity-duration relation that is likely to trigger debris flows, whereas the maximum threshold indicates the intensity above which debris flows will always oc-

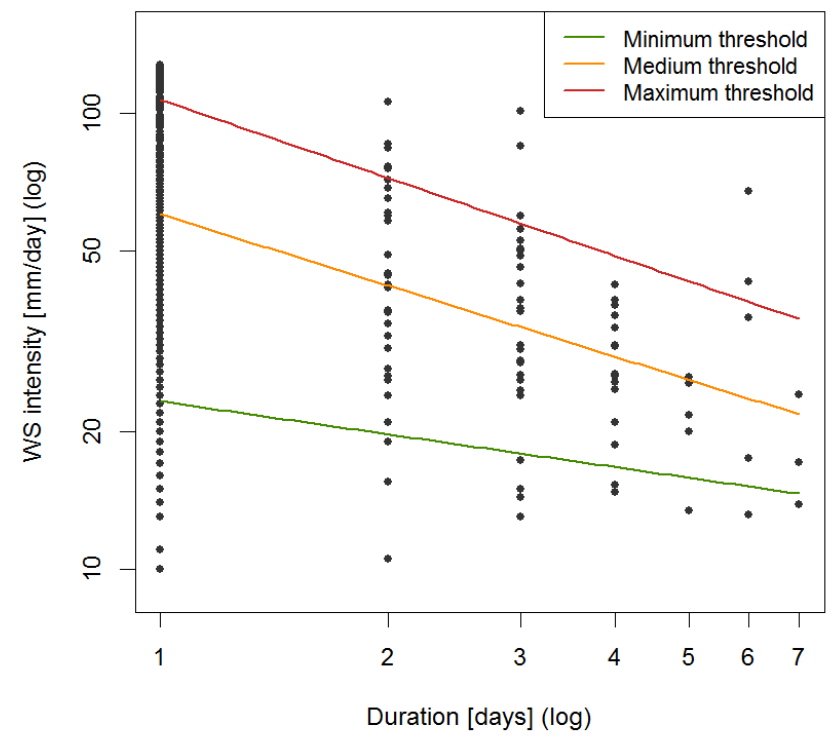

Fig. 4. Absolute ID threshold curves for debris flow initiation obtained from the water supply (WS) intensity 3-day moving average of the 5 th and 15 th percentiles (minimum threshold), the 45 th and 55th percentiles (medium threshold) and the 85th and 95th percentiles (maximum threshold) $(n=502)$.

cur. The three threshold levels are marked by the color code green, orange and red, which is common for indication of different warning levels in natural hazard research. Different warning levels in an early warning system are able to define different levels of preparedness. 


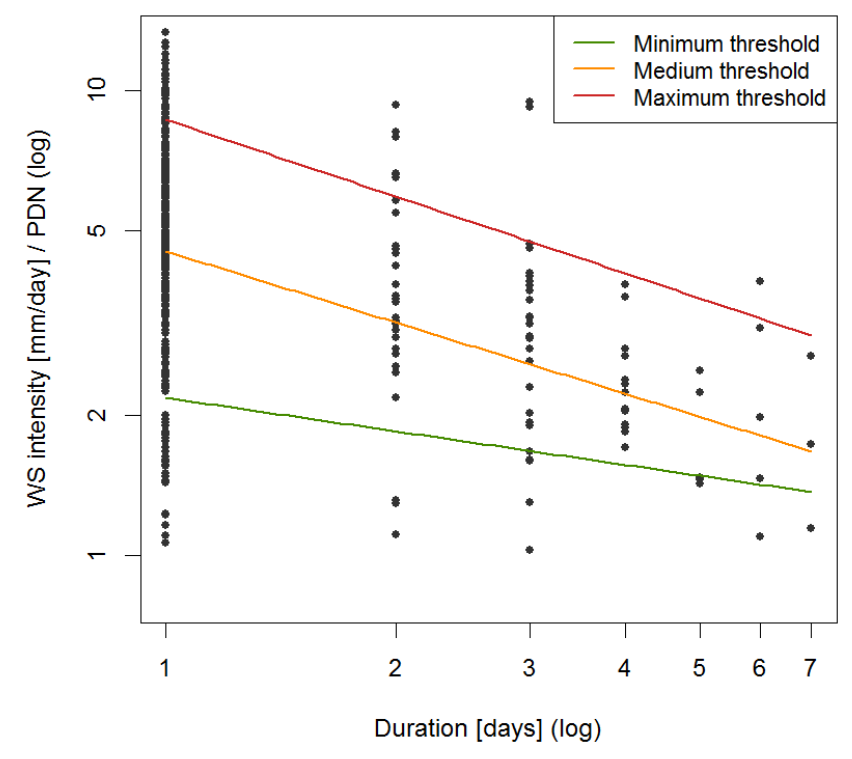

Fig. 5. Normalized ID threshold curves for debris flow initiation. Water supply (WS) intensities were normalized with the precipitation day normal (PDN). The curves were obtained from the 3-day moving average of the 5 th and 15 th percentiles (minimum threshold), the 45th and 55th percentiles (medium threshold) and the 85th and 95th percentiles (maximum threshold) $(n=502)$.

\section{Results}

\subsection{Absolute ID threshold}

The obtained absolute ID thresholds are represented in Fig. 4 and can be described with the following equations:

$\mathrm{I}_{\mathrm{MIN}}=23.3 \times \mathrm{D}_{\text {day }}^{-0.24}$

$\mathrm{I}_{\mathrm{MED}}=60.1 \times \mathrm{D}_{\text {day }}^{-0.52}$

$\mathrm{I}_{\text {MAX }}=107.2 \times \mathrm{D}_{\text {day }}^{-0.57}$

where $\mathrm{I}_{\mathrm{MIN}}$ is the lowest threshold level of water supply intensity in $\mathrm{mm} \mathrm{day}^{-1}$ above which debris flow initiation becomes possible, $\mathrm{I}_{\mathrm{MED}}$ is the intermediate threshold level above which debris flows become very likely, IMAX is the highest threshold level above which triggering of debris flows is almost assured and $\mathrm{D}_{\text {day }}$ is the corresponding duration in days. Critical water supply intensities calculated from the three thresholds over durations of 1,3 and 7 days are represented in Table 2.

The negative exponent characterizing all three threshold functions indicates that with increasing duration of water supply, the intensity that is needed for debris flow initiation decreases. Note that the three threshold curves show different slope angles with the maximum threshold curve showing the
Table 2. Critical water supply (WS) intensity calculated from the absolute minimum, medium and maximum ID threshold over durations of 1,3 and 7 days.

\begin{tabular}{llll}
\hline \multirow{2}{*}{ Duration [day] } & \multicolumn{3}{c}{ Critical WS intensity $\left[\mathrm{mm} \mathrm{day}^{-1}\right.$ ] } \\
& Minimum & Medium & Maximum \\
\hline 1 & 23 & 60 & 107 \\
3 & 18 & 34 & 57 \\
7 & 15 & 22 & 35 \\
\hline
\end{tabular}

Table 3. Range of critical water supply (WS) intensities calculated from the normalized minimum, medium and maximum ID threshold over durations of 1, 3 and 7 days. Different threshold intensities result from spatial variation of the precipitation day normal (PDN) (see Fig. 1).

\begin{tabular}{llll}
\hline \multirow{2}{*}{ Duration [day] } & \multicolumn{3}{c}{ Critical WS intensity $\left[\mathrm{mm} \mathrm{day}^{-1}\right]$} \\
& Minimum & Medium & Maximum \\
\hline 1 & $9-63$ & $18-131$ & $35-250$ \\
3 & $7-49$ & $10-75$ & $19-137$ \\
7 & $6-40$ & $7-48$ & $12-86$ \\
\hline
\end{tabular}

steepest slope. This implies that the water supply intensity to trigger debris flows has to be significantly higher in the shortterm than in the long-term. The medium threshold curve and the minimum threshold curve imply smaller differences in threshold intensity over time.

\subsection{Normalized intensity-duration threshold}

The obtained normalized ID thresholds are represented in Fig. 5 can be described with the following equations:

$\mathrm{I}_{\mathrm{MIN}} / \mathrm{PDN}=2.18 \times \mathrm{D}_{\text {day }}^{-0.24}$

$\mathrm{I}_{\mathrm{MED}} / \mathrm{PDN}=4.51 \times \mathrm{D}_{\text {day }}^{-0.51}$

$\mathrm{I}_{\mathrm{MAX}} / \mathrm{PDN}=8.66 \times \mathrm{D}_{\text {day }}^{-0.55}$

where $\mathrm{I}_{\mathrm{MIN}}$ is the lowest threshold level of water supply intensity $\left[\mathrm{mm} \mathrm{day}^{-1}\right], \mathrm{I}_{\mathrm{MED}}$ is the intermediate threshold level, $\mathrm{I}_{\text {MAX }}$ is the highest threshold level, PDN is the normalization parameter precipitation day normal and $\mathrm{D}_{\text {day }}$ is the corresponding duration in days. Critical water supply intensities calculated from the three thresholds over durations of 1,3 and 7 days are represented in Table 3. Because of normalization with the local parameter PDN, the critical water supply intensities obtained from the thresholds vary from location to location.

The spatial distribution of the normalized minimum, medium and maximum threshold over durations of 1,3 and 7 days is shown in Fig. 6. In accordance with the spatial distribution of the PDN (see Fig. 1), these maps show that 


\section{Duration of water supply (WS)}

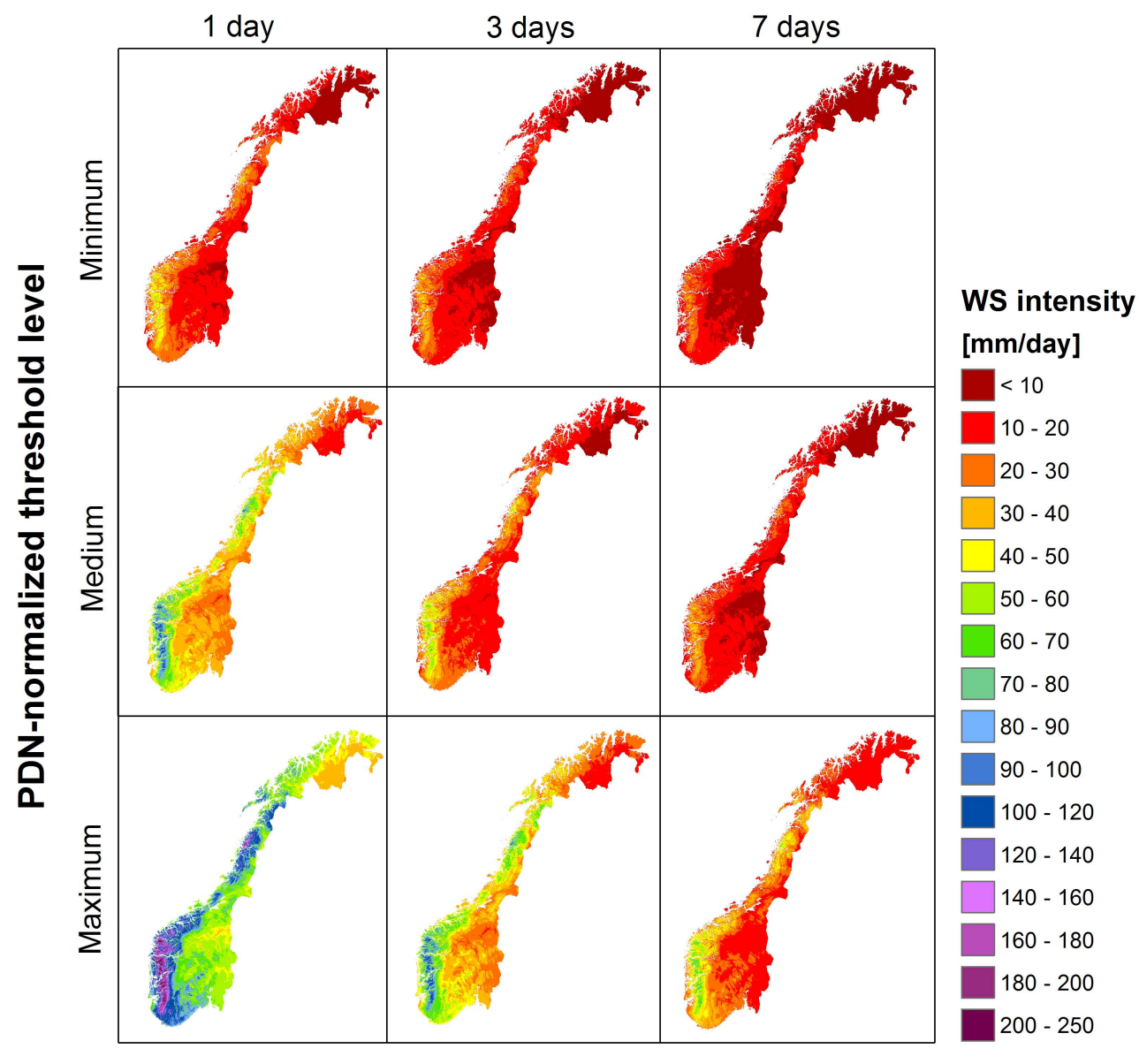

Fig. 6. Spatial distribution of the water supply (WS) intensity needed for debris flow initiation after 1 day, 3 days and 7 days of water supply according to the normalized minimum, medium and maximum ID threshold.

the intensity needed for debris flow initiation is considerably higher near the Norwegian west coast than in the drier eastern part of the country. The normalized minimum threshold ranges from 6 to $63 \mathrm{~mm} \mathrm{day}^{-1}$, the normalized medium threshold ranges from 7 to $131 \mathrm{~mm} \mathrm{day}^{-1}$ and the normalized maximum threshold varies from 12 to $250 \mathrm{~mm}_{\text {day }}{ }^{-1}$, depending on the specific location and the considered duration (see Table 3). Obviously, the variation of the minimum, medium and maximum threshold intensities in areas with low PDN is not as strong as the variation of the threshold intensities in areas with high PDN. This implies that the local PDN has a stronger impact on the threshold conditions in wetter areas than in drier areas.

For all three threshold levels, the spatial differences in water supply intensity values become smaller for longer durations. Especially in eastern Norway, the normalized ID thresholds are very low due to low PDN values. Thus, some parts of eastern Norway are characterized by a minimum threshold of less than $10 \mathrm{~mm} \mathrm{day}^{-1}$. In comparison, the absolute minimum ID threshold intensity ranges between $23 \mathrm{~mm} \mathrm{day}^{-1}$ over 1 day and $15 \mathrm{~mm} \mathrm{day}^{-1}$ over 7 days. In contrast, near the Norwegian west coast, the normalized ID thresholds are two to three times higher than the absolute ID thresholds. This is related to extremely high PDN values of up to $29 \mathrm{~mm} \mathrm{day}^{-1}$. Thus, the average intensity on a normal precipitation day on the west coast is occasionally higher than the intensity needed for debris flow initiation given by the absolute ID threshold for 1 day duration $\left(23 \mathrm{~mm} \mathrm{day}^{-1}\right)$. This implies a very frequent debris flow activity or a threshold that is too low for this wet region. This topic will be further discussed in Sect. 4.2.

\subsection{Frequency analysis of over-threshold events}

In order to estimate the probability of threshold exceedance, the annual frequency of water supply events with values higher than the thresholds obtained was calculated for the period 1981-2010 (approximately the period of time for which debris flow data is available). Figure 7 shows the spatial 


\section{Duration of water supply (WS)}

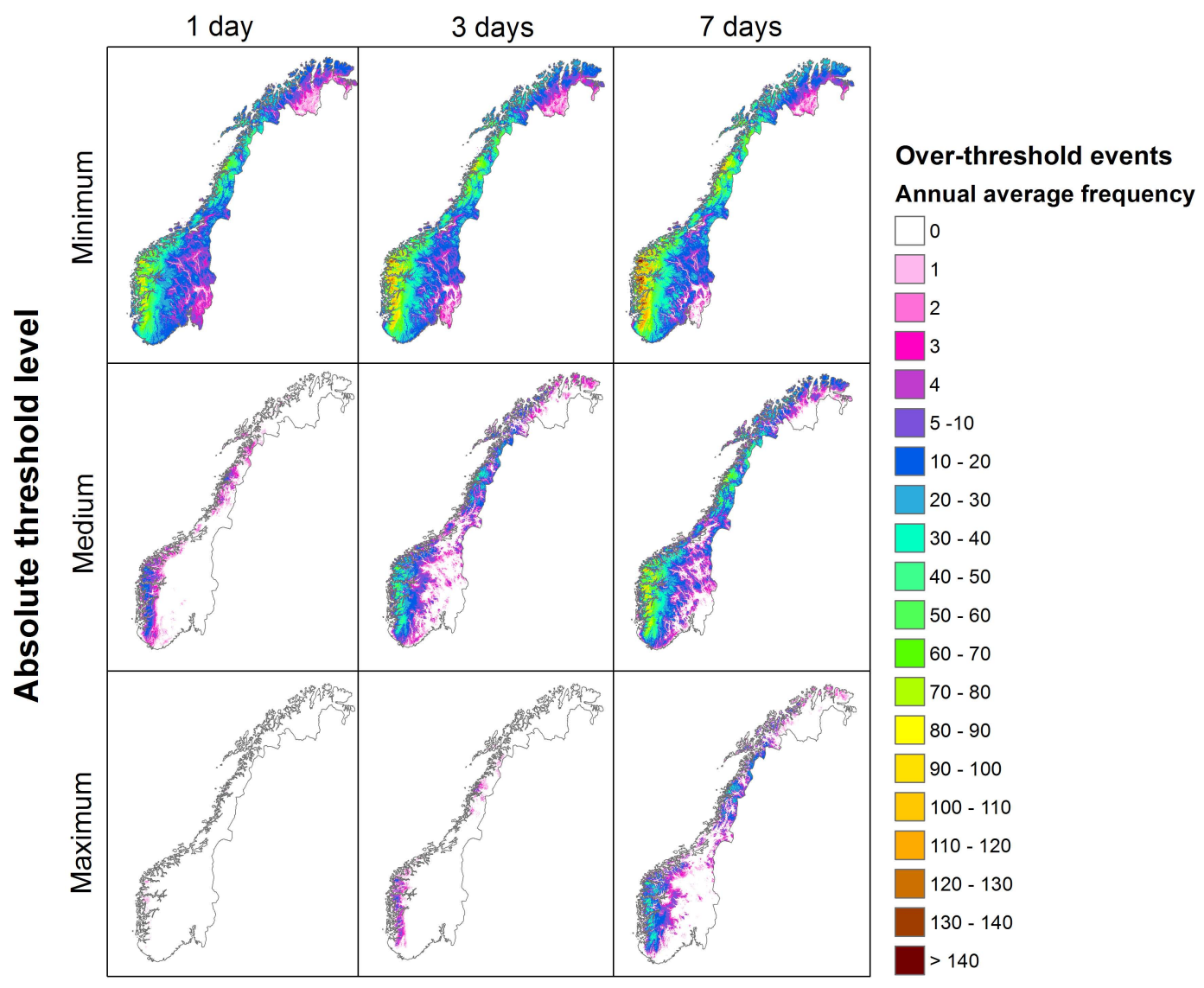

Fig. 7. Spatial distribution of the annual average frequency of over-threshold water supply events calculated from the absolute minimum, medium and maximum ID threshold for 1 day, 3 days and 7 days duration of water supply.

distribution of the annual average frequency of events above the absolute minimum, medium and maximum ID thresholds for durations of 1,3 and 7 days. Obviously the absolute minimum threshold is crossed most frequently. Furthermore, the threshold is more often exceeded along the west coast (in the area approximately from Stavanger in the south to Bodø in the north) and over longer durations. The absolute minimum threshold over 7 days can locally be exceeded as often as 160 times a year. However, the annual average frequency of over-threshold events decreases rapidly the higher the threshold level, the shorter the duration and the further east the location. Except at the very edge of the Norwegian west coast, the maximum threshold for the duration of 1 day is hardly ever exceeded.

Like the absolute thresholds, the exceedance probability of the normalized thresholds was estimated from the annual frequency of over-threshold events in the period 19812010 (Fig. 8). The annual frequency of water supply events that exceed the minimum threshold varies between 5 and 90 events depending on the location and the duration of water supply. As the water supply intensity has to be considerably higher for the medium threshold, the annual average number of over-threshold events decreases and ranges between 0 and 77 events. The frequency decreases further for the maximum threshold and varies, depending on duration and location, between 0 and 51 over-threshold events. From Fig. 7 it becomes clear that the threshold exceedance is more frequent over longer durations than over shorter durations. The frequency of over-threshold events is highest in western, northern and central Norway. Further differences in the spatial pattern of the exceedance frequency can be observed when comparing the different threshold levels. Thus, the minimum and medium thresholds are most frequently crossed along the west-facing slopes of the mountain ranges. The maximum threshold has the highest exceedance farther east in the flatter interior as well as in the far north. 


\section{Duration of water supply (WS)}

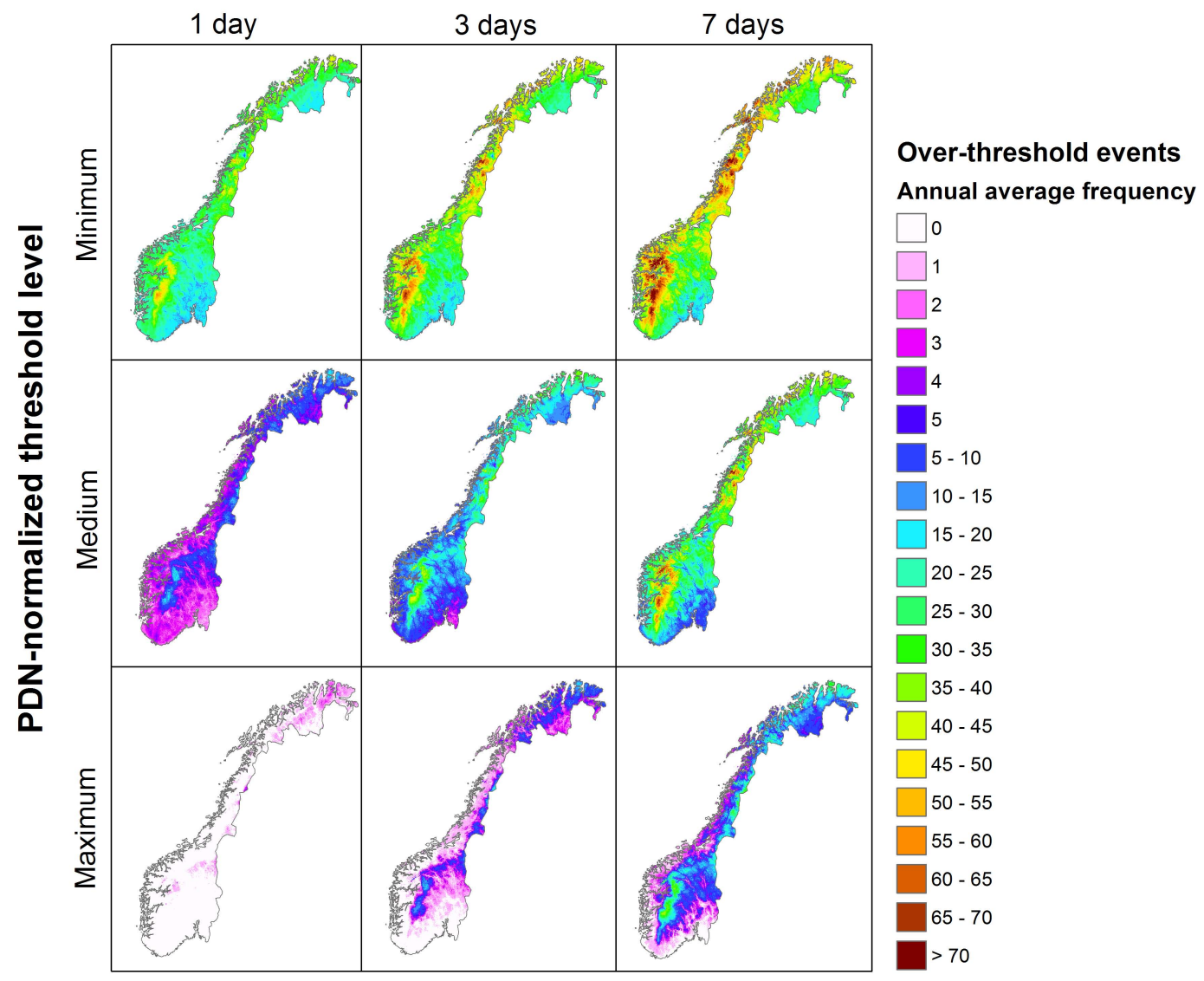

Fig. 8. Spatial distribution of the annual average frequency of over-threshold events calculated from the PDN-normalized minimum, medium and maximum ID threshold for 1 day, 3 days and 7 days duration of water supply.

\section{Discussion}

\subsection{Data reliability}

Due to several limitations, 146 debris flow events had to be excluded. The two main criteria for exclusion where: (1) Data extraction from the grids was not always possible due to missing water supply information at corresponding debris flow locations. This is mainly due to the coarse grid resolution of $1 \mathrm{~km} \times 1 \mathrm{~km}$ and the fact that grid cells with adjoining open water surfaces were not processed in the grid interpolation. As a result much of the coastal area is not covered. (2) For several debris flows no water supply was registered for the time of two days in advance of the debris flow event. Debris flows occurring after two dry days were considered as unlikely and therefore excluded. Possible reasons for weak correspondence between debris flow date/location and the corresponding water supply can be related to errors regarding the debris flow input data or to the water supply grid quality. The former can originate from (a) the fact that the debris flow documentation is incorrect in time and/or space; (b) the relocation of the event from the documented deposition point to a potential initiation point is incorrect; or (c) that the assumption regarding the triggering factor for debris flow initiation is incorrect. The latter is true for debris flows that were not induced by rainfall or snow melt but for example by human construction activities. However, the remaining data on 502 debris flow event were randomly checked manually for plausibility and showed good correspondences regarding their occurrence in time and space.

Generally, the quality of the water supply information is directly dependent on the quality of interpolation of the input grids for temperature and precipitation. Local gaps of the station network, the complex topography and the frequent occurrence of precipitation events in very local storm cells, are sources of uncertainty in the interpolated precipitation values. In addition, the temporal duration of extreme weather events can be very short, occasionally lasting less than an hour (Keefer et al., 1987). It is well known that the longer the period for which rainfall intensity is averaged, the smaller are the documented peak intensities (Guzzetti et al., 2007). Thus, 


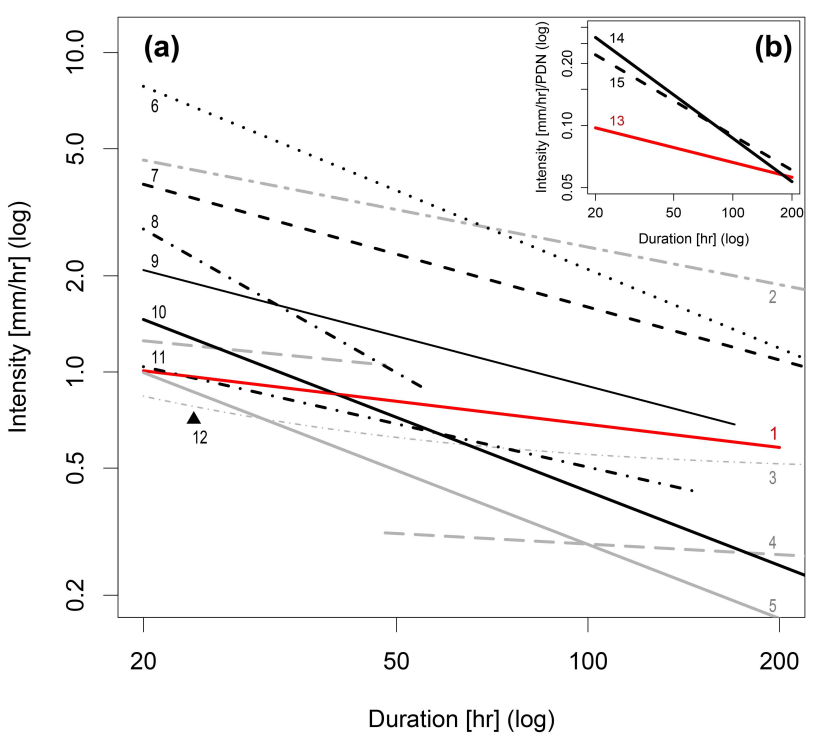

Fig. 9. The obtained absolute minimum threshold (1) and the obtained normalized minimum threshold (13) (both red) in comparison to a selection of other global (gray), regional and local (black) minimum ID thresholds. References for absolute thresholds in (a): Caine (1980) (2); Clarizia et al. (1996) (3); Crosta and Frattini (2001) (4); Guzetti et al. (2008) (5); Larsen and Simon (2003) for Puerto Rico (6); Ceriani et al. (1992) for Lombardy, Italy (7); Baum et al. (2005) for Seattle Area, US (8); Jakob and Weatherly (2003) (9), Moser and Hohensinn 1983 for Eastern Tyrol, Austria (10); Montgomery et al. (2000) for Oregon, US (11); Cepeda et al. (2010) for Norangselva, Western Norway (12). Reference for normalized thresholds in (b): Guzzetti et al. (2007) for mild climates (14) and Guzzetti et al. (2007) for highlands (15). Note that durations are given in hours $[\mathrm{h}]$.

the temporal resolution has a direct effect on the calculated intensities: the lower the temporal resolution, the lower the average intensity. The spatial resolution of $1 \mathrm{~km} \times 1 \mathrm{~km}$ and the temporal resolution of 1 day might be limiting factors for the purpose of threshold definition. However, at the present time the data used in this study are regarded as the best available on a national level (H. O. Hygen, personal communication, 2011).

\subsection{Threshold performance}

Both the absolute and the normalized thresholds are characterized by negative exponents and, thus, a log-linear decrease of intensity over time. The requirement of high water supply intensities over shorter durations corresponds to the common observation that the short-term water supply has to be considerably higher than the long-term water supply causing debris flow initiation (Wieczorek and Glade, 2005; Godt et al., 2006; Guzzetti et al., 2007; Dahal and Hasegawa, 2008). The relation between short-term and long-term water supply causing debris flow initiation (expressed by the steepness of the slope of a threshold curve) can be generally related to the infiltration and saturation capacity of the underlying sediments. Areas where the triggering short-term water supply intensity is orders of magnitude higher than the threshold intensity over longer periods should be characterized by a rather thick soil cover. If the infiltration capacity is high such a soil cover buffers high water supply intensities over shorter durations. As soil becomes saturated after long-lasting water supply, considerably lower triggering intensities are needed for debris flow initiation as in an unsaturated stage. Thus, the initiation of a debris flow is highly dependent on the duration. At locations with thinner soil cover intensities necessary for debris flow initiation are lower over short durations but approximate similar intensities over longer durations. Less water can be stored and, thus, antecedent water supply becomes less important. Here the difference between short-term and long-term threshold intensity is not as large.

The minimum threshold levels obtained in this study are in the range of other minimum intensity-duration (ID) thresholds described in literature (Fig. 9). In terms of the global absolute minimum thresholds, the threshold introduced by Caine (1980) is considerably higher than the threshold obtained in this study, while the thresholds from Crosta and Frattini (2001), and Guzzetti et al. (2008) are of comparable magnitude and show a similar slope. The two regional thresholds obtained in tropical and Mediterranean regions (Ceriani et al., 1992; Larsen and Simon, 2003) are three to eight times higher than the minimum threshold obtained for Norway. However, our threshold compares well to the regional and local minimum thresholds produced for temperate regions characterized by high annual precipitation, such as east Tyrol in Austria, western Canada and the northwestern US (Moser and Hohensinn, 1983, Montgomery et al., 2000; Jakob and Weatherly, 2003; Baum et al., 2005). The Norwegian west coast features a climate similar to northwestern North America. That our threshold is of comparable magnitude as the thresholds obtained for these regions can act as confirmation that the critical amount of rainfall/water supply for debris flow initiation shows a relationship with the common regional climate. The low short-term intensities and the lower slope of our threshold curve compared to other regional threshold curves can be related to a high percentage of bedrock area and a rather thin soil cover in large areas of mountain Norway, along with relatively coarse-grained glacially-derived sediments (Bogen, 1996). Thus, the water storage capacity is inherently low and the difference in threshold intensities over shorter and longer durations is relatively small. However, a limiting factor for the occurrence of debris flows is the availability of unconsolidated sediment and loose material. The magnitude of the minimum threshold obtained in this study is further supported by the study conducted by Cepeda et al. (2010). For a small catchment on the Norwegian west coast, he found a threshold of $17 \mathrm{~mm} \mathrm{day}^{-1}$ to be critical for debris flow initiation (see Fig. 8a; hourly average value indicated by triangle symbol). Since his threshold does not account for water supplied by 

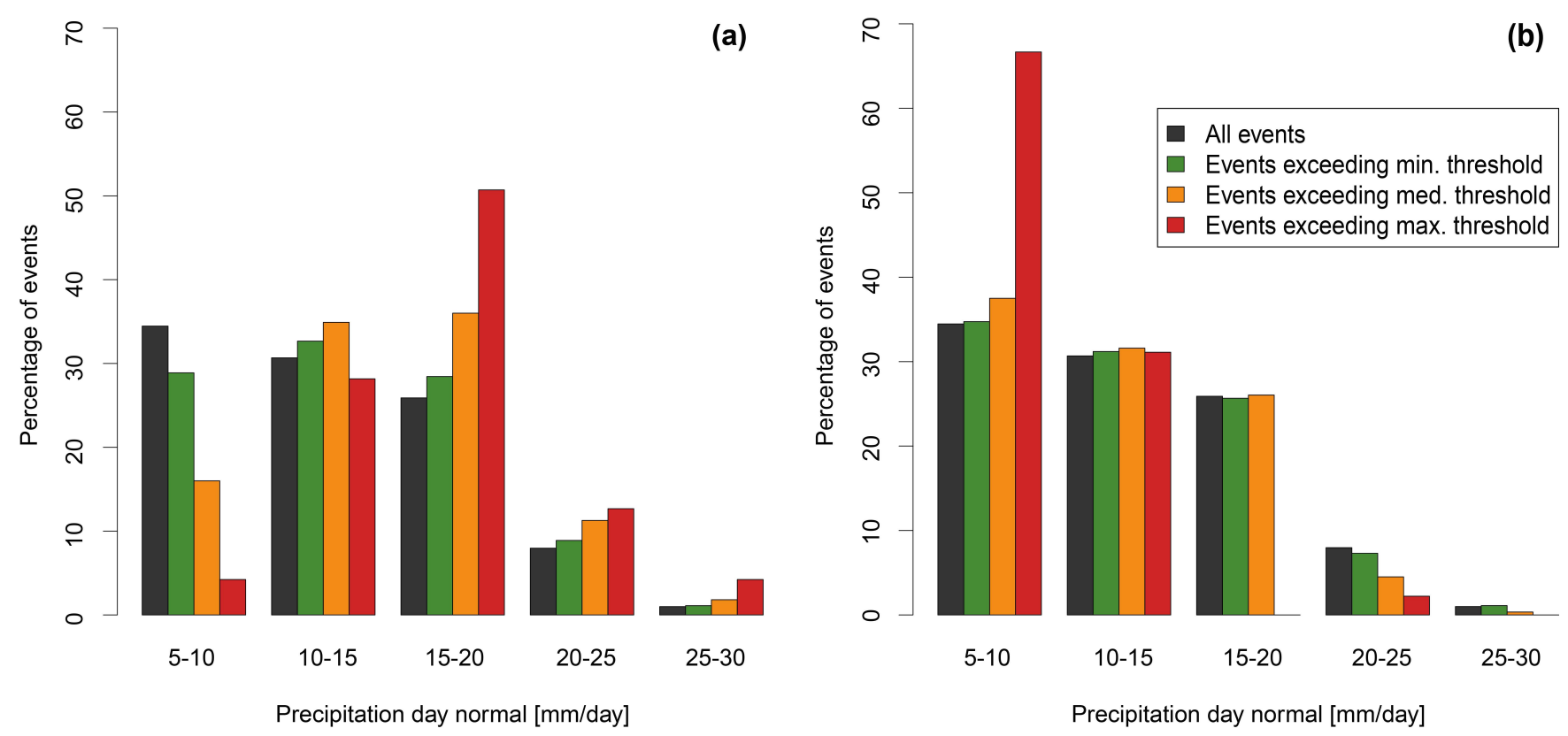

Fig. 10. Percentage of events captured by the absolute thresholds (a) and the normalized thresholds (b) according to precipitation day normal (PDN) classes: 5-10 mm, 10-15 mm, 15-20 mm, 20-25 mm, 25-30 mm. Dark bars show the distribution of the entire number of events over the five classes, while the colored bars show the percentage of those events captured by the minimum, medium and maximum thresholds in each class respectively.

snow melt but merely for rainfall, it corresponds well with the slightly higher threshold we obtained in this study.

The normalized minimum threshold obtained in this study is considerably lower than the two thresholds Guzzetti et al. (2007) proposed for mild mid-latitude and for mountain climates in central and southern Europe (see Fig. 8b). It turns out that, despite normalization, significant differences remain between regions. This mismatch is also assessed by Guzzetti et al. (2007). They point out that although the rainy/precipitation day normal is a good normalization parameter, regional differences in threshold levels might arise from true spatial variability, the lack of spatially equal data coverage and discrepancies in the method used for threshold definition. However, it is observed that for longer durations the intensities needed for debris flow initiation become more similar. This tendency suggests that the local characteristics become less important for debris flow initiation the longer the duration of water supply lasts.

The comparison of the absolute and normalized minimum threshold obtained in this study to other minimum ID thresholds extracted from literature reveals that the threshold levels obtained are reasonable. A further test of threshold reliability was conducted by statistical analyzes, as shown in the density plots in Fig. 10. The minimum, medium and maximum threshold levels calculated for the 502 debris flow events are compared to the actual ID relationship extracted for each debris flow event to estimate the capture percentage of the different thresholds. These data are spatially grouped into five different classes according to the local precipitation day nor- mal (PDN) and plotted against the total number of events in that specific class. The comparison of the number of captured events with the entire event population (both presented as density bars in the histograms) enables the estimation of spatial clustering of captured and/or missed events for areas characterized by a certain PDN.

Figure 10a shows the capture of debris flow events by the absolute thresholds related to the corresponding PDN class of the event location. Compared to the total number of debris flow events within the lowest PDN class $(5-10 \mathrm{~mm})$ it can be observed that the captured debris flow events are clearly underrepresented by all three thresholds, which in turn implies that the threshold levels might be too high for those dry regions. On the other hand, debris flow events in areas with a higher PDN (15-20, 20-25 and 25-30 mm precipitation $\mathrm{day}^{-1}$ ) are captured over proportionally often by the minimum, medium and maximum thresholds and are, thus, overrepresented in relation to the total number of events. Apparently, in these areas the threshold intensity is lower than the water supply intensity that is actually needed to trigger debris flows. The underestimation of the threshold intensity results in a higher number of captured events but will also lead to a higher number of false alarms. Only the absolute thresholds in the moderately wet areas (PDN class $10-15 \mathrm{~mm}$ ) perform well in accordance with the total number of debris flow events. Here, the minimum, medium and maximum thresholds seem to fit the actual conditions that are needed for debris flow initiation. It is further noted that the density of debris flow events captured by the maximum threshold for 
all PDN-classes shows the strongest divergence in relation to the total number of events. The most probable reason for this discrepancy is the lower data density that is available for the analysis of the spatial reliability of the maximum threshold $(n=71)$.

Figure $10 \mathrm{~b}$ shows the total number of debris flow events compared to the number of events captured by the normalized thresholds, again classified according to the local PDN. It can be observed that debris flow events captured by the minimum and the medium thresholds are in good agreement with the total number of events in all PDN classes. The good fit indicates that the normalized minimum and medium thresholds are able to account for regional differences in critical threshold conditions for debris flow initiation. The agreement of captured and total number of events also confirms that there exists a dependency between local hydro-meteorological characteristics and threshold intensity. However, the maximum threshold performs less well than the minimum and medium thresholds. The number of captured debris flow events is strongly skewed towards the driest PDN class $\left(5-10 \mathrm{~mm}\right.$ precipitation day $\left.{ }^{-1}\right)$. Similar to the absolute maximum threshold, this discrepancy can partly be a result of the low data density $(n=45)$, but it is most likely the consequence of unrealisticly high threshold intensities (up to $250 \mathrm{~mm} \mathrm{day}^{-1}$ ) calculated for areas with high PDN. This is confirmed by the low exceedance frequency of the normalized maximum threshold along the Norwegian west coast and a higher frequency of over-threshold events in the east where estimated critical threshold intensities are lower (see Fig. 9). Thus, in very wet regions, the threshold intensity for debris flow initiation is clearly overestimated. There seems to be an upper limit for threshold intensities that will always trigger debris flows, and this upper limit appears to be lower than $200 \mathrm{~mm} \mathrm{day}^{-1}$. However, despite the overestimation of the maximum threshold in wet areas, the normalized thresholds clearly show a better performance than the absolute thresholds. Thus, the normalized thresholds should be preferred over the absolute thresholds for the purpose of early warning. However, in any application of the results presented in this paper, one should keep in mind that the frequency of overthreshold events might change significantly over relatively short time scales. This is related to the expected change in the spatial and temporal patterns of extreme precipitation events in Norway due to climate change (Dyrrdal et al., 2011).

In summary the frequency analysis of over-threshold events reveals that the absolute thresholds are most often exceeded along the edge of the Norwegian west coast, while the normalized thresholds have the highest rate of exceedance on the west-facing slopes of the central, western and northern mountain ranges. Since the normalized thresholds were assessed to be more reliable and the frequency analysis based on them can serve as an estimation of exceedance probability, the western face of the mountain ranges is regarded as the most debris flow prone region of Norway. This implies that it is not necessarily the areas with the highest mean annual precipitation (MAP) or the highest precipitation day normal (PDN) that have the highest hydro-meteorological susceptibility for debris flow initiation.

\subsection{Uncertainty in thresholds}

A critical issue related to water supply thresholds is the assessment of the uncertainty related to threshold definition. This is especially true as such thresholds might be used for the design of debris flow early warning systems. Some of this uncertainty is epistemic and can be reduced as more high quality data becomes available, but much of it is aleatory (natural) and can never be eliminated. The results shown on Fig. 10 give some indication of the reliability (or lack thereof) of the thresholds derived in this study. As expected, these thresholds perform much better than other general (global) thresholds presented in Fig. 9 for the conditions in Norway. However, the uncertainty in their performance is still significant and its quantification is not straightforward. Cepeda et al. (2010) and Medina-Cetina and Nadim (2008) discuss dealing with uncertainty of rainfall thresholds in the context of early warning systems.

\section{Conclusions}

This study defines two sets of intensity-duration (ID) thresholds for triggering of debris flows in Norway. Using information on rainfall and snow melt the actual amount of supplied water was estimated in order to derive these thresholds. The inclusion of snow melt in the analyzes represents a step forward as compared to earlier studies as this factor is regarded as highly important for debris flow initiation in Norway, especially during spring time.

The main conclusions of our study can be summarized as follows:

- For both set of thresholds obtained in this study the intensities needed for debris flow initiation decrease as the duration of water supply increases. However, the slope of the threshold curve is quite smooth indicating the high portion of bedrock area and the rather thin soil cover.

- Comparison with the scientific literature shows that the minimum thresholds obtained in this study are in the range of the thresholds obtained for regions with a climate comparable to Norway (e.g., Western US and Canada).

- A statistical test of threshold capture percentage revealed that the normalized minimum and medium ID thresholds show the best performance when compared to the actual distribution of debris flow events. 
- The calculated frequency of over-threshold events (defined by the normalized thresholds) in the period 19812010 was highest on the west-facing slopes of the Norwegian mountain ranges. This indicates that this area has a hydro-meteorological regime that promotes the initiation of debris flows.

Acknowledgements. The authors wish to thank Egil Syre (NGI) for his help with GIS tasks and José Mauricio Cepeda (NGI) for his comments on the threshold issue. C. Huggel, one anonymous reviewer and editor D. Keefer provided constructive comments that helped to enhance the quality of the paper. Funding for this study was provided by the International Centre for Geohazards (ICG) and the InfraRisk project (http://infrarisk.ngi.no) financed by the Norwegian Research Council, the Norwegian Public Roads Administration and the Norwegian National Rail Administration.

Edited by: D. Keefer

Reviewed by: C. Huggel and one anonymous referee

\section{References}

Baum, R. L. and Godt, J. W.: Early warning of rainfall-induced shallow landslides and debris flows in the USA. Landslides 7, 259272, 2010.

Baum, R. L., Godt, J. W., Harp, E. L., and McKenna, J. P.: Early warning of landslides for rail traffic between Seattle and Everett, Washington. Proceedings 2005 International Conference on Landslide Risk Management, 731-740, 2005.

Bjordal, H. and Helle, T. E.: Skred og flom på veg, Report of the Norwegian Public Road Authority, 5, 2011 (in Norwegian).

Bogen, J.: Erosion and sediment yield in Norwegian rivers. Proceedings of the Exeter Symposium, 73-94, 1996.

Brunetti, M. T., Peruccacci, S., Rossi, M., Luciani, S., Valigi, D., and Guzzetti, F.: Rainfall thresholds for the possible occurrence of landslides in Italy, Nat. Hazards Earth Syst. Sci., 10, 447-458, doi:10.5194/nhess-10-447-2010, 2010.

Caine, N.: The rainfall intensity-duration control of shallow landslides and debris flows. Geogr. Ann. A 62, 23-27, 1980.

Cannon, S. H. and Ellen, S.: Rainfall conditions for abundant debris avalanches in the San Francisco Bay region, California, California Geology 38, 267-272, 1985.

Cepeda, J., Høeg, K., and Nadim, F.: Landslide-triggering rainfall thresholds: A conceptual framework, Q. J. Eng. Geol. Hydrogeol., 43, 69-84, 2010.

Ceriani, M., Lauzi, S., and Padovan, N.: Rainfall and landslides in the Alpine area of Lombardia Region, central Alps, Italy. Interpraevent International Symposium 2, 9-20, 1992.

Crosta, G.: Regionalization of rainfall thresholds: an aid to landslide hazard evaluation. Environ. Geol. 35, 131-145, 1998.

Crosta, G. B. and Frattini, P.: Rainfall-thresholds for triggering soil slips and debris flow. Proceedings of the 2nd EGS Plinius Conference on Mediterranean Storms, 463-487, 2001.

Crosta, G. B. and Frattini, P.: Rainfall-induced landslides and debris flows, Hydrol. Process., 22, 473-477, 2008.
Dahal, R. K. and Hasegawa, S.: Representative rainfall thresholds for landslides in the Nepal Himalaya, Geomorphology, 100, 429443, 2008.

Dyrrdal, A. V., Isaksen, K., and Hygen, H. O.: Past changes in frequency, intensity, and spatial occurrence of meteorological triggering variables relevant for natural hazards in Norway, Met.no report 3, 2011.

Engeset, R., Tveito, O.E., Alfnes, E., Mengistu, Z., Udnæs, H.-C., Isaksen, K., and Førland, E. J.: Snow map system for Norway. NHP report 48, 112-121, 2004.

Frattini, P., Crosta, G., and Sosio, R.: Approaches for defining thresholds and return periods for rainfall-triggered shallow landslides, Hydrol. Process., 23, 1444-1460, 2009.

Førland, E. J.: Nedbørens høydeavhengighet, Klima 1, 3-24, 1979 (in Norwegian with English summary).

Godt, J. W., Baum, R. L., and Chleborad, A. F.: Rainfall characteristics for shallow landsliding in Seattle, Washington, USA, Earth Surf. Proc. Land., 31, 97-110, 2006.

Guzzetti, F., Peruccacci, S., Rossi, M., and Stark, C. P.: Rainfall thresholds for the initiation of landslides in central and southern Europe, Meteorol. Atmos. Phys., 98, 239-267, 2007.

Guzzetti, F., Peruccacci, S., Rossi, M., and Stark, C. P.: The rainfall intensity-duration control of shallow landslides and debris flows: an update, Landslides 5, 3-17, 2008.

Hungr, O., McDougall, S., Wise, M., and Cullen, M.: Magnitudefrequency relationship of debris flows and debris avalanches in relation to slope relief, Geomorphology 96, 355-365, 2008.

Innes, J. L.: Debris flows, Prog. Phys. Geog., 7, 469-501, 1983.

Jaedicke, C., Lied, K., and Kronholm, K.: Integrated database for rapid mass movements in Norway, Nat. Hazards Earth Syst. Sci., 9, 469-479, doi:10.5194/nhess-9-469-2009, 2009.

Jakob, M. and Weatherly, H.: A hydroclimatic threshold for landslide initiation on the North Shore Mountains of Vancouver, British Columbia, Geomorphology 54, 137-156, 2003.

Keefer, D. K.: Landslides caused by earthquakes, B. Geol. Soc. Am., 95, 406-421, 1984.

Keefer, D. K., Wilson, R. C., Mark, R. K., Brabb, E., Brown, W. M., Ellen, S. D., Harp, E. L., Wieczorek, G. F., Alger, C. S., and Zatkin, R. S.: Real-time landslide warning during heavy rainfall, Science 238, 921-925, 1987.

Larsen, M. C. and Simon, A.: A rainfall intensity-duration threshold for landslides in a humid-tropical environment, Puerto Rico. Geogr. Ann. A, 75, 13-23, 1993.

Medina-Cetina, Z. and Nadim, F.: Stochastic design of an early warning system, Georisk Special Issue: Assessment and Management of Risk for Engineered Systems and Geohazards, 2, 223-236, 2008.

Montgomery, D. R., Schmidt, K. M., and Greenberg, H. M.: Forest clearing and regional landsliding, Geology, 28, 311-314, 2000.

Nadim, F., Cepeda, J., Sandersen, F., Jaedicke, C., and Heyerdahl, H.: Prediction of rainfall-induced landslides through empirical and numerical models. Proceedings of the First Italian Workshop on Landslides (IWL 2009), Naples, Italy, 8-10 June, 206-215, 2009.

Rapp, A. and Nyberg, R.: Alpine debris flows in northern Scandinavia, Geogr. Ann. A, 63, 183-196, 1981.

Rebetez, M., Lugon, R., and Baeriswyl, P. A.: Climatic change and debris flows in high mountain regions: The case study of the Ritigraben torrent (Swiss Alps), Climatic Change, 36, 371-389, 
1997.

Rickenmann, D. and Zimmermann, M.: The 1987 debris flows in Switzerland - documentation and analysis, Geomorphology 8, 175-189, 1993.

Saito, H., Nakayama, D., and Matsuyama, H.: Relationship between the initiation of a shallow landslide and rainfall intensity-duration thresholds in Japan, Geomorphology, 118, 167-175, 2010.

Saloranta, T. M.: Simulating snow maps for Norway: description and statistical evaluation of the seNorge snow model, The Cryosphere Discuss., 6, 1337-1366, doi:10.5194/tcd-6-13372012, 2012.

Sandersen, F., Bakkehøi, S., Hestnes, E., and Lied, K.: The influence of meteorological factors on the initiation of debris flows, rockfalls, rockslides and rockmass stability, edited by: Senneset, K., Landslides A. A. Balkema Publishers, Rotterdam, 97-114, 1996.

Statens Kartverk: Terrengmodell - Landsdekkende digital terrengmodell i 10 eller 20 meters rutenett, Product sheet published by the Norwegian Mapping Authority, 2011 (in Norwegian).
Tveito, O. E., Bjørdal, I., Skjelvag, A. O., and Aune, B.: A GISbased agro-ecological decision system based on gridded climatology, Meteorol. Appl., 12, 57-68, 2005.

Wieczorek, G. F.: Landslide triggering mechanisms, in: Landslides - Investigation and Mitigation. Special Report 247, edited by: Turner, A. K. and Schuster, R. L., National Academy Press, Washington D.C., 76-90, 1996.

Wieczorek, G. F. and Glade, T.: Climatic factors influencing occurrence of debris flows, in: Debris flows and related phenomena, edited by: Jakob, M. and O. Hungr, Springer Verlag, 325-362, 2005.

Wilson, R. C. and Jayko, A. S.: Preliminary maps showing rainfall thresholds for debris flow activity, San Francisco Bay region, California, Open File Report US, Geological Survey, 1997.

Zimmermann, M.: Debris flows 1987 in Switzerland: geomorphological and meteorological aspects. Proceedings of the Hydrology in Mountainous Regions, Lausanne, IAHS publications 194, 387-393, 1990. 